\title{
Voice Controlled Notice Board Display with Android Application
}

\author{
Habibulla Mohammad, Katta Bhavana, Gajula Trilok, Dugginapalli Sirisha, \\ Konkimalla Rohith Sai
}

\begin{abstract}
Now-a-days notice board plays a crucial role in many institutes/organizations or in railway stations, bus stands, schools, hospitals and in many other public places. Paper notices stacked on the notice board is a time lagging, cost effective process which includes wastage of time, paper and human work. The main purpose of the notice board is used to view the information in an efficient way to the people, on the other hand to update the messages immediately is not easy on the notice board. This project, deals about an advanced Hi-Tech wireless communicated Notice Board.

We are introducing a new "VoiceTotext.apk" android application software which would convert the voice to text. It works on all android platforms, but also it can work with a working internet in the mobiles or any other PC's.
\end{abstract}

Keywords: Notice Board, Internet, Android App, Paper Notices, Smart Phones, messages.

\section{INTRODUCTION}

We come across many circumstances where we need to desperately need to display notices on a screen. For areas like railway stations and other busy shopping malls the station master/announcer need not have to type in every announcement message manually in order to display on the screen. We bring up a creative idea of voice controlled advanced notice board. It can work without typing physically. We have already looked at the GSM based Electronic bulletin board, but speech-controlled board has extra benefit which is simple to use. Voice identification is finished within our developed android application. User needs to install this app in their mobile.

This system is magnified to display the latest information through an Android application of smart phones or tablet. The span of mobile technology opens the windows towards

Revised Manuscript Received on February 05, 2020.

* Correspondence Author

Habibulla Mohammad*, Senior Assistant Professor, Department of ECE, PVPSIT, Kanuru,Vijayawada, India.

E-mail: honeyhabeeb@gmail.com

Katta Bhavana, Department of ECE, PVP Siddhartha Institute of Technology,Kanuru,Vijayawada, India.

Rohit Sai, Department of ECE, PVP Siddhartha Institute of Technology,Kanuru,Vijayawada, India.

Gajula Trilok, Department of ECE, PVP Siddhartha Institute of Technology,Kanuru,Vijayawada, India.

Dugginapalli Sirisha, Department of ECE, PVP Siddhartha Institute of Technology,Kanuru,Vijayawada, India.

(C) The Authors. Published by Blue Eyes Intelligence Engineering and Sciences Publication (BEIESP). This is an open access article under the CC BY-NC-ND license (http://creativecommons.org/licenses/by-nc-nd/4.0/) the android apps. The websites are disappearing now and the mobile phones are playing the prominent role. It's the time to change the path from the custom websites and other things to apps, which has become major part of our daily routine.

\section{TECHNOLOGY USED}

\section{A. Bluetooth}

Bluetooth wireless technology could also be a latest mode technique within the communication arena, and it's one altogether the quickest growing fields within the wireless technologies. Here in this system Bluetooth technology is ready to receive and transmit the information wirelessly between the devices. Speech synthesis is just the artificial reproduction our human speech. In this an inbuilt google voice system is used.

Table 1: Pin description of Bluetooth module having transmitter and receiver part

\begin{tabular}{|c|c|c|c|}
\hline $\begin{array}{c}\text { PIN } \\
\text { NO }\end{array}$ & PIN NAME & TYPE & DETAILS \\
\hline 1 & RST & - & reset \\
\hline 2 & N/C & - & No Connection \\
\hline 3 & RXD & Input & $\begin{array}{c}\text { Serial Port } \\
\text { Receive data } \\
\text { (TTL level) }\end{array}$ \\
\hline 4 & TXD & Output & $\begin{array}{c}\text { Serial Port } \\
\text { Transmit data } \\
\text { (TTL level) }\end{array}$ \\
\hline 5 & GND & - & Ground \\
\hline 6 & VCC & Input & $\begin{array}{c}\text { Voltage DC } \\
\text { input }\end{array}$ \\
\hline 7 & KEY & - & AT Mode Key \\
\hline
\end{tabular}

Bluetooth receiver part will receive the incoming voice message and transmitter part will transmit the information that is received from the phone/tablet which is connected to a microcontroller thereby the message is displayed on LCD display.

\section{B. Microcontroller}

Micro Controller is design to perform embedded task with dedicated processing which suggests you merely need one unit to perform a task i.e. clock, trimming or display. Each Unit will look out of the dependencies it needs to perform the functionality with low resource and accurate results. With low resource the budget will reduce remarkable which induce most of the Engineer to make great point with affordability. 
The Atmega328 could also be a really fashionable microcontroller chip produced by Atmel. it's an 8-bit microcontroller that has $32 \mathrm{~K}$ of nonvolatile storage, $1 \mathrm{~K}$ of EEPROM, and $2 \mathrm{~K}$ of internal SRAM. The Atmega328 is one of the microcontroller chips that are used with the favoured Arduino Duemilanove boards.

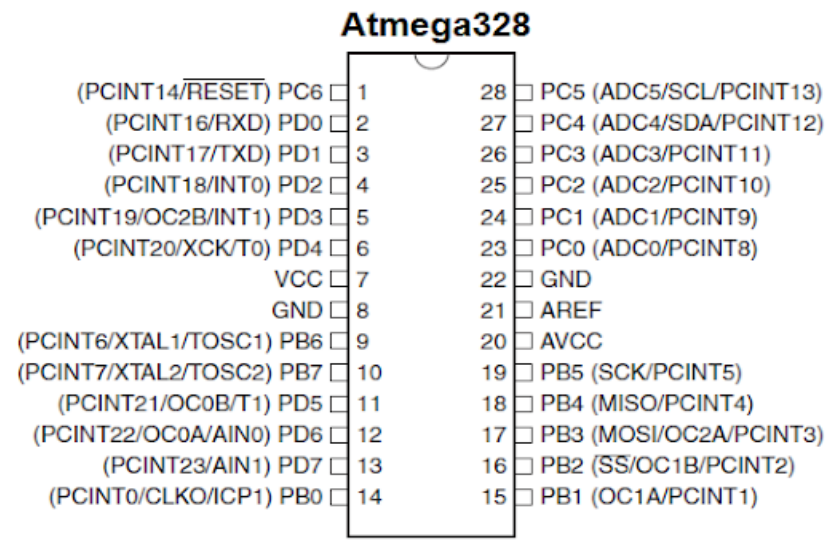

\section{Figure1: Pin description of ATMEGA 328P Microcontroller.}

\section{LITERATURE SURVEY}

Prof. Nawale Shubhangi et.al [1]: In this paper they conveyed a notion to style an SMS based automatic display panel which may restore the contemporary programmable electronic display. it's been proposed to style a display panel that has been programmed via a licensed mobile. This will be utilized in every place where message is conveyed in less time.

Mr. Ramchandra K. Gurav [2]: This paper, had been focused on GSM (Global System for Mobile) technology that designed a contemporary bulletin board." Wireless bulletin board employing a GSM System" it's a wireless module which sends the message wirelessly with the assistance of GSM module. Means user or designated person can equip to send the message from anywhere and therefore the message is displayed on LCD display. Additionally, this message is additionally sent to each one whose number is stored in memory. Everyone receives the message personally. Whenever a replacement message is received it gives a sign by the buzzer.

A. Meenachi et.al [3]: This paper directing on Wireless E-Notice Board Using Wi-Fi and Bluetooth Technology. This paper put forth a new idea of communicating the message to the people working on wireless electronic board which was integrated with the assistance of the Wi-Fi technology. this is often getting utilized in conveying any message almost instantaneously with none delay just by sending an SMS that's better and reliable than the old regular method of communicating the message on bulletin board. This advanced modern method is often utilized in huge institutions, several busy places, malls or in construction areas to extend the reliability of the safety system and also alert the general public just in case of any emergency breaks out and avoid any devastating accidents.

Abhishek Gupta et.al [4]: The foremost purpose of this paper being published is to showcase the event of a wireless electronic notice board that shows the message sent from the user and to style a simplistic, easy thanks to install, user-friendly system, which may receive and show the notice during a correct method keeping the aspect of date and time in mind, which assists the user to effortlessly keep the track of the notice board a day and each time the system is employed by the user. GSM and Wi-Fi module for data transmission. In this, paper they used Wi-Fi module for data transmission. during this project, the most drawback of using Wi-Fi is network failure.

R.G.Gupta et al. [5]: In this paper it's primarily being focused on designing an electronic bulletin board for various sectors like schools. The notice is often sent wirelessly within a second. These creative techniques are often wont to display the newest information. The contents of notice are often changed anytime. the thought was to style an SMS based automatic display panel which may reconstruct the present used programmable electronic display. it's been proposed to style a display panel that has been programmed via a licensed mobile. The message to be displayed was transferred through an SMS from a transmitter. The microcontroller collects the SMS and certifies the sent Mobile Identification.

Neenu Ann George et.al [6]: This paper shares out with the implementation of the voice-based system by using Bluetooth with the assistance of the android application. It uses a Raspberry pi. It needs an android application for voice recognition. The communication is formed feasible by using Bluetooth module. the main output of this work being done was to make a sensible bulletin board that worked during a well-organized method that kept track of date and time which helped the user to effortlessly keep in contact of the bulletin board a day and every time he operate the system and convey the knowledge more effectively.

Prof. Leena H. Patil et.al [7]: In this paper it's mainly focused on displaying any message soon with no hold up just by sending voice through SMS display on the LCD. The short messages are displaying on the bulletin board. The developed system will therefore aim's in wirelessly sending the short information with intended users and also helps in saving the time and thus the value for paper work.

It is user friendly system, which may display notice about information during a particular way .so that the user can help keep track of the knowledge easily a day and each time. Android may be a set of software for mobile devices including Operation System.

Prachee U. Ketkar et.al [8]: This paper mainly specializes in the difficulties of wiring that we'd like to beat by reducing the complexness within the system design. Majority of the companies are manufacturing audio / video systems like public announcement system, CCTV, programmable sign boards etc. But of these systems are generally hardwired, complex in nature and difficult to expand. So, by including the feature of wireless communication interface like GSM to those systems, we will overcome their limitations.

Smt. M. Baby et.al [9]: In this practical paper sms based wireless electronic bulletin board explains the explanation for establishing an efficient and reliable communication between a mobile and a microcontroller using GSM modem. 
This GSM based electronic bulletin board has several applications which are very useful altogether domains including banks, stoke exchanges, control public advertisements, educational sector i.e., in schools and colleges etc. altogether the above mentioned applications we'll use a GSM MODEM, but with slightly change in hardware also in conjunction with this we are getting able to explain you ways this applications are mostly utilized in low time-to-market and thus due to development of the software resulting low NRE (Non -recurring Engineering).This technical paper plays a prominent role within the state-of-the-art scenario to develop authentic and pocket friendly products where the important time market is relentlessly shrinking.

\section{FLOWCHART}

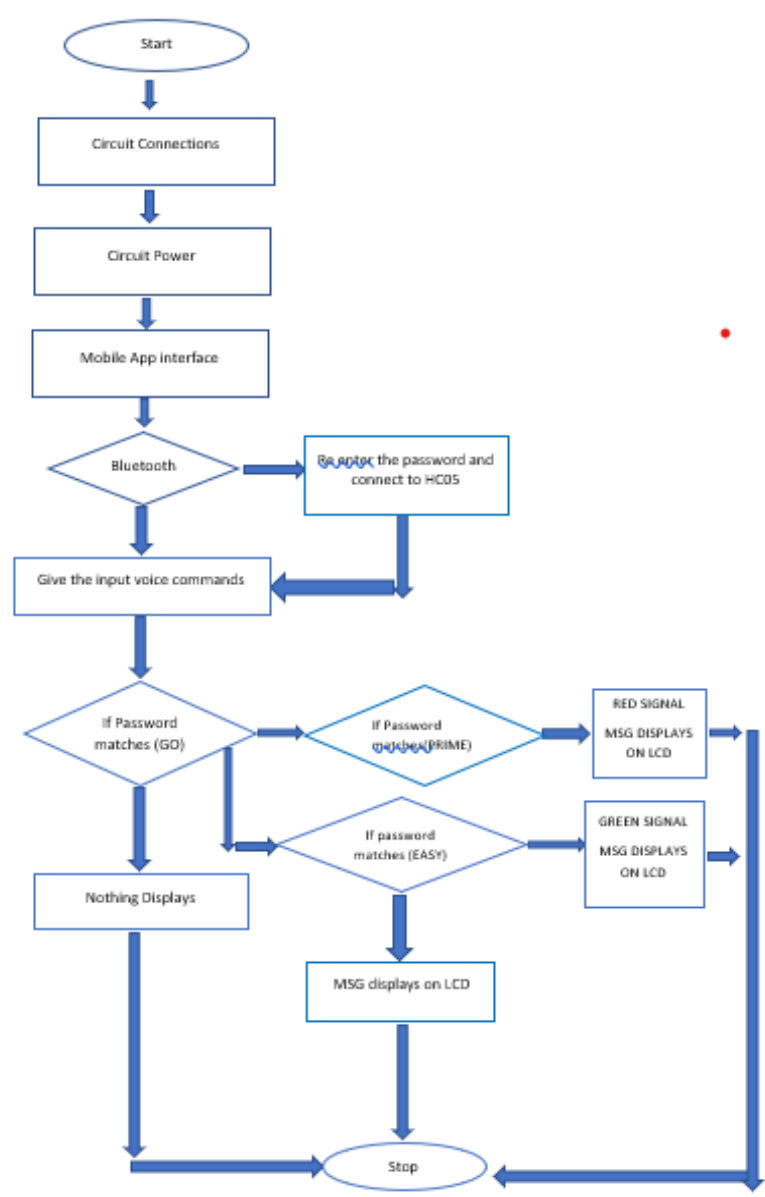

Figure 2: Showing Flow Chart of Notice Board controlled by Voice Commands

\section{A. Algorithm}

Step 1: Circuit connections should be made.

Step 2: Power supply is connected to the circuit.

Step 3: Mobile and notice board are paired through the android application with Bluetooth technology concept.

Step 4: Check the Bluetooth connection.

Step 5: If Bluetooth is connected then the device is ready to accept the voice commands

Step 6: If the input password matches to " go prime" or "go easy" it will display the information according with the alert signal.
Step 7: If the password doesn't match, then again check the Bluetooth connection and re-enter the password again. Step 8: When there is no work just switch off the power supply.

\section{SOFTWARE USED}

\section{A. Android Studio:}

Android Studio is that the official integrated development environment (IDE) for Android application development. it's supported Java environment for software, and incorporates its code editing and developer tools [10].

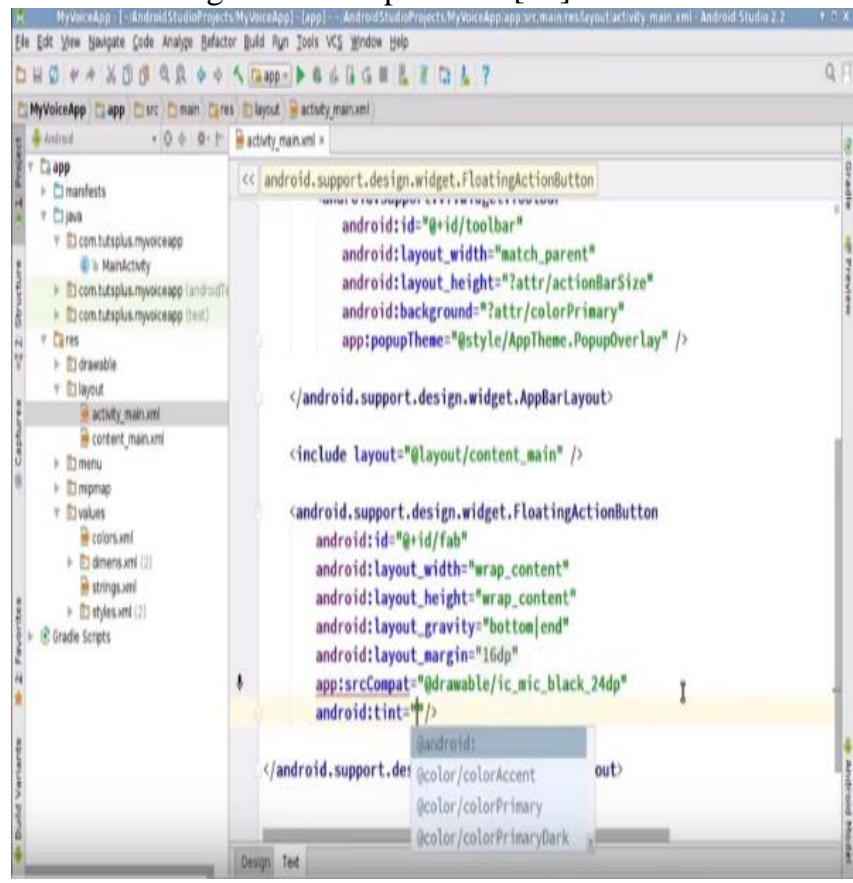

Figure 3: Android studio for the creation of voice controlled app.

\section{METHODOLOGY}

In this we have made the project using Java framework Technology.

\section{A. JAVA:}

It is the foremost popular programming language for Android smartphone applications and is additionally among the foremost favoured for the event of edge devices and also to the internet of things. The ritualistic language for Android development is Java. The best parts of Android are inscribed in Java and its APIs are outlined primarily from Java. Java is used mainly for web, mobile Desktop Applications, enterprise applications. Java could also be used as a general-purpose programming language which is concurrent, class based, object-oriented. Java is precisely designed to possess as a little number of implementation dependencies as possible.

\section{B. XML:}

This helps you to model your app, how it will look, how components like buttons, text view, etc., will be placed and their styling.

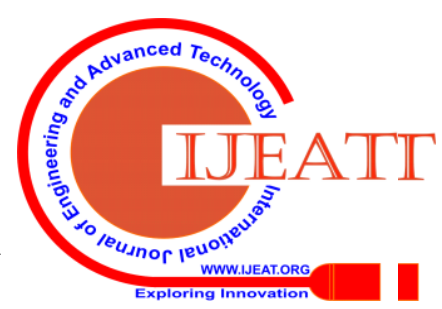


Apart from these, $\mathrm{xml}$ is additionally used for parsing data either from database or server into your android app [11].

This is used to design a group of regulations for encryption of documents with an arrangement that's both human-readable and machine-readable.

\section{ANDROID:}

Android may be a Linux based OS it's designed primarily for touch screen mobile devices like smart phones and tablet computers.

It is a strong OS and it supports sizable amount of applications in Smartphones. These applications are easier and advanced for the users. These applications can be created by the developers using Arduino studio or any other software's and these can be downloaded, installed or can be removed. All these are supported by the android OS platform.

These apps are programmed using Java technology and run through a Java virtual machine (JVM) that is optimized for mobile devices.
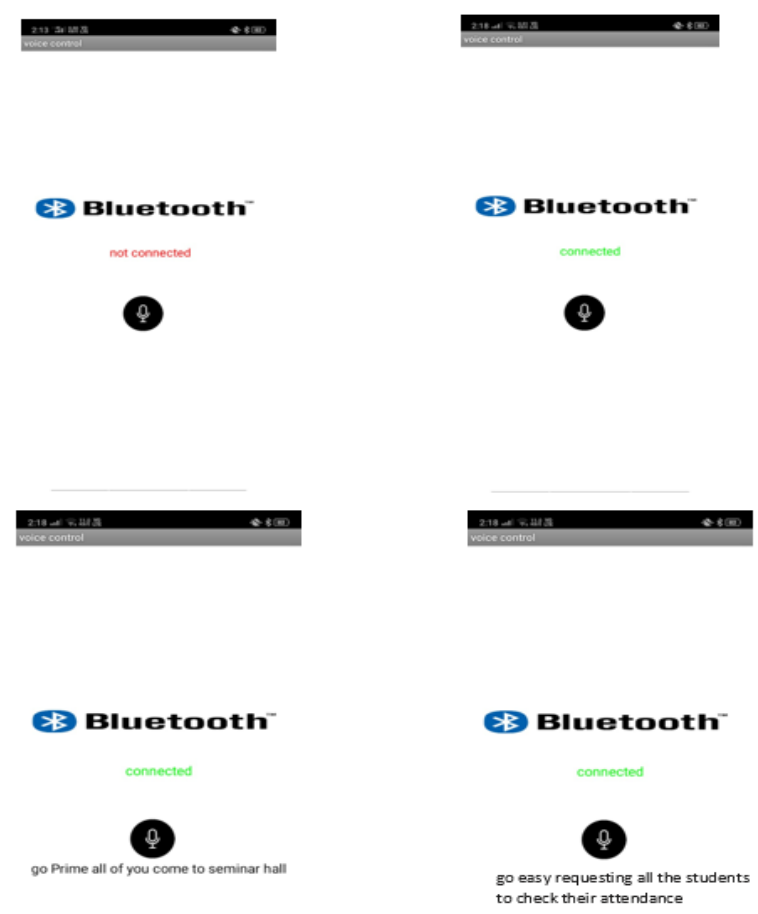

Figure 4: Showing the android app interfacing with the Bluetooth module in a mobile.

\section{CURRENT SETUPS OF NOTICE BOARD}

In previous days normal paper notice boards are used which is very complex and time-consuming process later on Now days, GSM electronic equipment based mostly notice boards are in use, however, they need router during which cable connections are done which create it complicated.

\section{PROPOSED WORK}

By considering increasing compactness of electronic systems, there is a desire of embedding two or a lot of systems along. This project is an implementation of a thought of wireless communication between a mobile and an Arduino controller.
In this the voice commands are recognized by the android application. The mobile or tablet is interfaced to microcontroller through a wireless communication called Bluetooth. Bluetooth will transmit the information to Microcontroller which is directly in contact with the display screen [12].

The important information can be conveyed by giving a red alert signal and other information regarding any type of quick calls can be displayed along with green alert signal. By giving the alerts people can estimate the intensity of the message and they can respond in an effective manner.

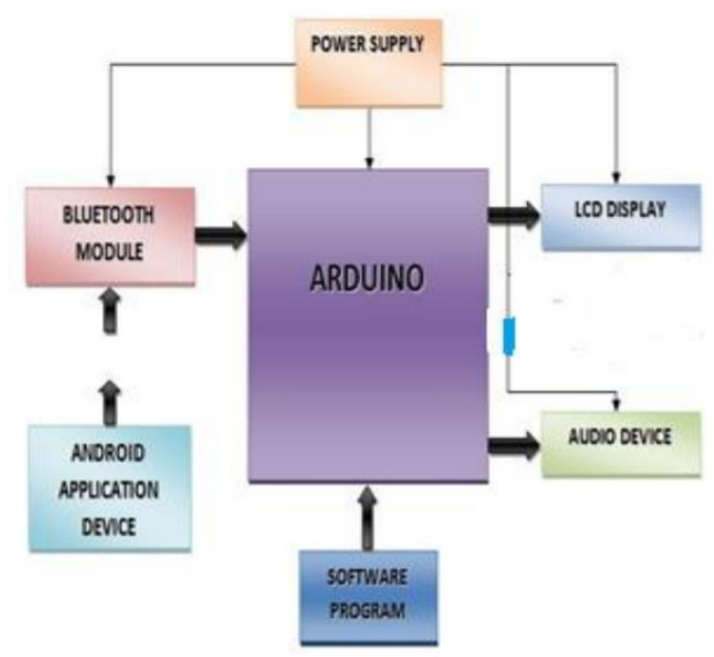

Figure 5: Block Diagram showing the notice board setup

Bluetooth is associate degree open wireless protocol for exchanging information over short distances from mobile devices, making Personal area Networks (PANs). Bluetooth can receive the signal sent by the automaton application device (mobile phone), then send this signal to the microcontroller.

Android application is having the potential to perform the following functions:

1) Converting the voice command data to text.

2) Send this received text over to microcontroller through blue tooth for displaying on notice board display.

We are creating a notice board that displays the required information which is controlled by our voice commands given through the android application with the assistance of Bluetooth module.

\section{RESULT}

The unifying idea of this project is that when the user speaks to the android which includes an app. that converts speech-to-text, and the text messages are going to be displayed on the LCD display within the classroom. 
1. The proposed method was successfully designed and therefore the required data was displayed with respective alert signals of red or green on the LCD.

2. The Serial data is sent from the android application and therefore the data is received by the Bluetooth receiver that interfaced to the microcontroller.

3. After a while the info was automatically deleted/updated

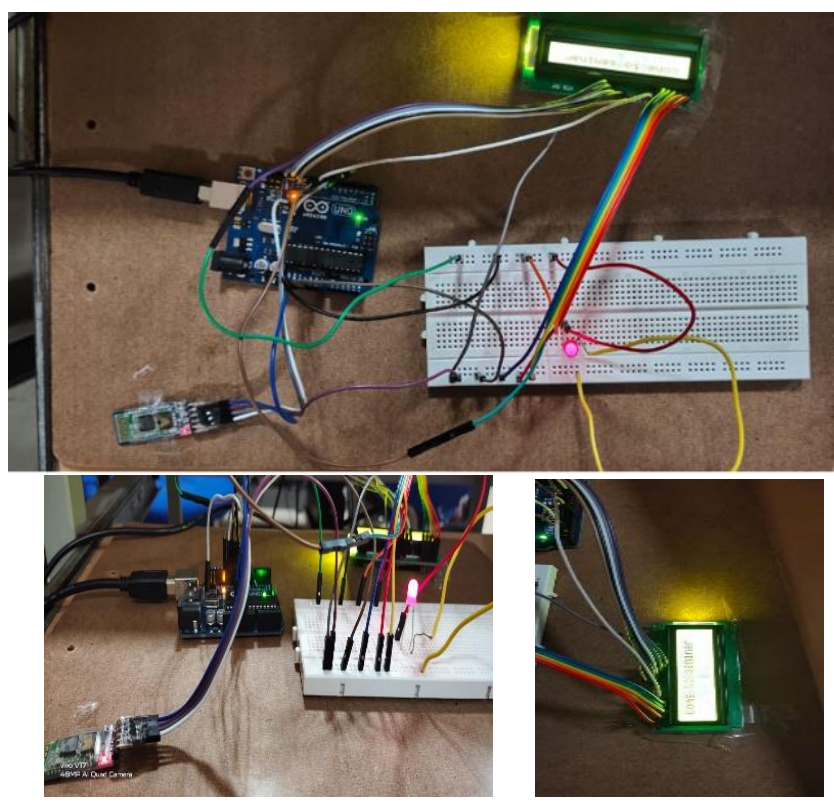

Figure 6: Notice board displaying the information with alert signal

\section{CONCLUSION}

This system was developed to enable the people wirelessly in transmitting notices on bulletin board using Bluetooth. This contributes immensely in making communication with greater efficiency. Thus, it displays the messages with fewer errors and maintenance. The paper on voice controlled bulletin board brings a complicated means of transferring notices with delay (time limit). This way we will display the notices for extended period. we will also provide notices at just one occasion along side their respective delay. This makes our work easy by not giving the notices after certain period. Thus, it helps to access notices during a simple and well organized manner. Therefore smart bulletin board proves to be serviceable in any organizations.

\section{APPLICATIONS}

1) It can be made useful majorly in colleges, schools, bus stands and railway stations.

2) Controlling machines by just saying instructions in the industries.

3) For the sake of emergency calls in Military applications.

4) It can be used in malls \& highways for advertisement purpose.

\section{FUTURE SCOPE}

1. Later user can interact with Google directly. Latest news and updates can be known through this application.
2. Bluetooth can be replaced with GSM module or Zigbee for further extension in terms of range.

3. Security can be maintained by allowing only authorized users. Only by them the device can be handled.

4. When there is no information to display instead of keeping it idle simply, we can display the temperature which is one such theoretical improvement that is well possible.

5. Feedback system can be implemented.

\section{REFERENCES}

1. Prof. R. G. Gupta, Nawale Shubhangi, TupeUsha, Waghmare Priyanka. Android based Enotice board. International Journal of Advance Research and Innovative Ideas in Education (IJARIIE). 2016

2. Mr.Ramchandra K. Gurav, Mr.RohitJagtap. Wireless digital notice board using GSM technology. International Research Journal of Engineering and Technology (IRJET). 2015; 02(09).

3. A. Meenachi, S. Kowsalya, P. Prem Kumar. Wireless ENotice board using Wi-Fi and Bluetooth technology. Journal of Network Communications and Emerging Technologies (JNCET). 2016.

4. Abhishek Gupta, Rani Borkar, SamitaGawas, Sarang Joshi. GSM based wireless notice board. International Journal of Technical Research and Applications. 2016; 30-33p. [5]

5. Prof.R.G.Gupta,NawaleShubhangi,TupeUsha,WaghmarePriyanka. Android based Enotice board. International Journal of Advance Research and Innovative Ideas in Education (IJARIIE). 2016

6. Neenu Ann George, Prabitha. P, Priyanka. A.K, Ershad. S.B. Raspberry Pi based speech recognition sensed smart notice board display. IJSRD - International Journal for Scientific Research \& Development. 2016.

7. Prof. Leena H. Patil, Vidya M. Parkhi, Kavita D. Gomase, Mayur S. Shende. Voice Message's Displaying on LCD.IJSRD - International Journal for Scientific Research \& Development| Vol. 5, Issue 07, 2017.

8. Prachee U.Ketkar1, Kunal P.Tayade2, Akash P. Kulkarni3, Rajkishor M.Tugnayat4. "GSM Mobile Phone Based LED Scrolling Message Display System". International Journal of Scientific Engineering and Technology (ISSN : 2277-1581) Volume 2 Issue 3, PP : 149-155 1 April 2013.

9. Smt. M. Baby, P. Harini, M. Sailaja, K. Annie Sumantha. SMS based wireless E-Notice board. International Journal of Emerging Technology and Advanced Engineering (IJETAE). 2013; 3(3).

10. https://www.quora.com/Do-I-need-Android-Studio-to-develop-Andro id-apps

11. https://www.vogella.com/tutorials/JavaXML/article.html https://components101.com/wireless/hc-05-bluetooth-module

\section{AUTHORS PROFILE}

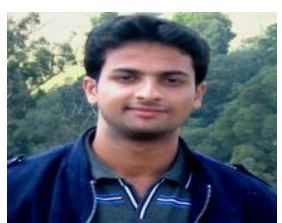

Habibulla Mohammad working as Senior Assistant Professor in ECE Department, Prasad V. Potluri Siddhartha Institute of Technology, Kanuru Total Journal articles 11 and,Conference Papers 04.Presently a member in Research and Development Cell, PVPSIT 